\title{
Generalized Quasilinearization for the System of Fractional Differential Equations
}

\author{
Peiguang Wang ${ }^{1}$ and Ying $\mathrm{Hou}^{2}$ \\ ${ }^{1}$ College of Electronic and Information Engineering, Hebei University, Baoding 071002, China \\ ${ }^{2}$ College of Mathematics and Computer Science, Hebei University, Baoding 071002, China \\ Correspondence should be addressed to Peiguang Wang; pgwang@mail.hbu.edu.cn
}

Received 9 December 2012; Accepted 8 February 2013

Academic Editor: Yongsheng S. Han

Copyright (c) 2013 P. Wang and Y. Hou. This is an open access article distributed under the Creative Commons Attribution License, which permits unrestricted use, distribution, and reproduction in any medium, provided the original work is properly cited.

\begin{abstract}
This paper considers the initial value problems of the system of fractional differential equations and constructs two monotone sequences of upper and lower solutions. By using quasilinearization technique, monotone sequences of approximate solutions that converge quadratically to a solution are obtained.
\end{abstract}

\section{Introduction}

In this paper, we consider the system of Caputo fractional differential equations:

$$
{ }^{c} D^{q} x=f(t, x), \quad x\left(t_{0}\right)=x_{0},
$$

where $0<q<1, f \in C\left[\Omega, R^{n}\right], \Omega=[(t, x): \alpha(t) \leq x \leq \beta(t)$, $\left.\alpha, \beta \in C^{q}\left[J, R^{n}\right], t \in J\right]$, and $J=\left[t_{0}, T\right]$.

The theories and properties of fractional differential equations have received attention from some researchers because many mathematical modeling appeared in the fields of physics, chemistry, engineering and biological sciences and so on. For examples and details, we can refer to the, monographs of Miller and Ross [1], Podlubny [2], Kilbas et al. [3], and West et al [4] and the papers of Debnath [5], Rossikhin and Shitikova [6], and Ferreira et al [7]. There are many results on the basic theory of initial value and boundary value problems for fractional differential equations, which can be found in [8-10]. Meanwhile, there are some qualitative and numerical solutions for various fractional equations with delay and impulsive effects. For details, see some recent papers [11-18] and the references therein.

It is well known that the monotone iterative technique is an ingenious method providing a constructive approach to find solutions for the nonlinear problem via linear iterates. Lakshmikantham and Vatsala [19], and McRae [20] investigated the existence of minimal and maximal solutions of fractional differential equations by establishing a comparison result and using the monotone method, respectively; Benchohra and Hamani [21] used a monotone iterative technique in the presence of lower and upper solutions to discuss the existence of solutions to impulsive fractional differential inclusions.

Quasilinearization [22] provides an elegant and easier approach to obtain a sequence of approximate solutions with quadratic convergence, and the method has been extended to fractional differential equations in $[23,24]$. However, to the best of our knowledge, there are few results for the system of fractional differential equations, especially results on the convergence of the system. In the present paper, we will discuss the approximate solutions of the system of fractional differential equations through the application of quasilinearization. The significance of this work lies in the fact that the system of fractional differential equations can also obtain a monotone sequence of approximate solutions converging uniformly to the solution of the problem and possessing quadratic convergence.

The nonhomogeneous linear system of Caputo fractional differential equations is given by

$$
{ }^{c} D^{q} x=B x+g(t, y), \quad x\left(t_{0}\right)=x_{0},
$$

where $B$ is an $n$th order matrix over complex field, and $g$ is an $n$-dimensional locally integrable column vector function on $J$. 
Using the method of successive approximations, we get the solution of (2) as

$$
\begin{aligned}
x(t)= & x_{0} E_{q}\left(B\left(t-t_{0}\right)^{q}\right)+\left(t-t_{0}\right)^{q-1} E_{q, q} \\
& \times\left(B\left(t-t_{0}\right)^{q}\right)^{k} g(t, y), \quad t \in J,
\end{aligned}
$$

where

$$
E_{q}(B)=\sum_{k=0}^{\infty} \frac{B^{k}}{\Gamma(q k+1)}, \quad E_{q, q}(B)=\sum_{k=0}^{\infty} \frac{B^{k}}{\Gamma(q k+q)}
$$

are Mittag-Leffler functions of one parameter and two parameters, respectively.

\section{Preliminaries}

Now, we present the following definition and lemma which help to prove our main result.

Definition 1. Let $\alpha, \beta \in C^{q}\left[J, R^{n}\right]$ be lower and upper solutions of (1) if they satisfy the inequalities

$$
\begin{aligned}
& { }^{c} D^{q} \alpha \leq f(t, \alpha), \quad \alpha_{0} \leq x_{0}, \\
& { }^{c} D^{q} \beta \geq f(t, \beta), \quad \beta_{0} \geq x_{0},
\end{aligned}
$$

respectively, for $t \in J$.

Lemma 2. Suppose that $\alpha, \beta \in C^{q}\left[J, R^{n}\right]$ are lower and upper solutions of (1), and

$\left(\mathrm{H}_{1}\right) f \in C\left[\Omega, R^{n}\right]$ are quasimonotone nondecreasing in $x$ for each $t \in J$ and for each $i \in I=\{1,2, \ldots n\}$,

$$
f_{i}(t, x)-f_{i}(t, y) \leq L \sum_{j=1}^{n}\left(x_{j}-y_{j}\right)
$$

where $x \geq y, L \geq 0$ is a constant.

Then, $\alpha\left(t_{0}\right) \leq \beta\left(t_{0}\right)$ implies that $\alpha(t) \leq \beta(t)$.

Proof. Firstly, suppose that

$$
{ }^{c} D^{q} \beta>f(t, \beta), \quad{ }^{c} D^{q} \alpha \leq f(t, \alpha), \quad t \in J
$$

and $\alpha\left(t_{0}\right)<\beta\left(t_{0}\right)$. We will prove that $\alpha(t)<\beta(t), t \in J$. Suppose the conclusion is not true, then the set

$$
\mathbb{Z}=\bigcup_{i=1}^{n}\left[t \in J, \beta_{i}(t) \geq \alpha_{i}(t)\right]
$$

is nonempty.

Let $t_{1}=\inf \mathbb{Z}$. Certainly, $t_{1}>0$. Since the set $\mathbb{Z}$ is closed, $t_{1} \in \mathbb{Z}$ and consequently there exists a $j$ such that $\beta_{j}\left(t_{1}\right)=$ $\alpha_{j}\left(t_{1}\right)$. Moreover, $\beta_{i}\left(t_{1}\right) \geq \alpha_{i}\left(t_{1}\right)$, for $i \neq j$, and

$$
\alpha_{j}(t)<\beta_{j}(t), \quad t \in\left[0, t_{1}\right) .
$$

Hence, it easily follows that

$$
{ }^{c} D^{q} \alpha_{j}\left(t_{1}\right) \geq{ }^{c} D^{q} \beta_{j}\left(t_{1}\right) .
$$

This together with the quasimonotonicity of $f$ yields

$$
\begin{aligned}
f_{j}\left(t_{1}, \alpha\left(t_{1}\right)\right) & \geq{ }^{c} D^{q} \alpha_{j}\left(t_{1}\right) \geq{ }^{c} D^{q} x \beta_{j}\left(t_{1}\right) \\
& >f_{j}\left(t_{1}, \beta_{j}\left(t_{1}\right)\right) \geq f_{j}\left(t_{1}, \alpha\left(t_{1}\right)\right),
\end{aligned}
$$

which leads to a contradiction.

In order to prove the case of nonstrict inequalities, consider the functions

$$
\tilde{\beta}_{i}(t)=\beta_{i}(t)+\varepsilon e^{(n+1) L_{i} t},
$$

where $\varepsilon>0$ is sufficiently small constant. Then using (6), we have

$$
\begin{aligned}
{ }^{c} D^{q} \widetilde{\beta}_{i}(t) & ={ }^{c} D^{q} \beta_{i}(t)+(n+1) \varepsilon L_{i} e^{(n+1) L_{i} t} \\
& \geq f_{i}(t, \beta(t))+(n+1) \varepsilon L_{i} e^{(n+1) L_{i} t} \\
& \geq f_{i}(t, \tilde{\beta}(t))-n \varepsilon L_{i} e^{(n+1) L_{i} t}+(n+1) \varepsilon L_{i} e^{(n+1) L_{i} t} \\
& >f_{i}(t, \tilde{\beta}(t)) .
\end{aligned}
$$

Also $\widetilde{\beta}_{i}\left(t_{0}\right)>\alpha_{i}\left(t_{0}\right)$. Now using the result corresponding to strict inequalities, we get

$$
\alpha_{i}(t)<\widetilde{\beta}_{i}(t)=\beta_{i}(t)+\varepsilon e^{(n+1) L_{i} t}, \quad t \in J .
$$

Letting $\varepsilon \rightarrow 0$, we obtain the required result and the proof is complete.

Corollary 3. The function $f(t, \alpha)=\sigma(t) \alpha$ where $\sigma(t) \leq L$ is admissible in Lemma 2 to yield $\alpha(t) \leq 0, t \in J$.

\section{Main Result}

Theorem 4. Assume that $\alpha_{0}, \beta_{0} \in C^{q}\left[J, R^{n}\right]$ are lower and upper solutions of (1) such that $\alpha_{0}(t) \leq \beta_{0}(t), t \in J$, and

$\left(\mathrm{H}_{1}\right) f, \phi \in C\left[\Omega, R^{n}\right]$ are quasimonotone nondecreasing in $x$ for $t \in J, f_{x}, \phi_{x}, f_{x x}, \phi_{x x}$ exist and are continuous on $\Omega$, satisfying $f_{x x}+\phi_{x x} \geq 0, \phi_{x x} \geq 0$;

$\left(\mathrm{H}_{2}\right) a_{i j}\left(t, \alpha_{0}, \beta_{0}\right) \geq 0, i \neq j$, where $A\left(t, \alpha_{0}, \beta_{0}\right)=$ $\left[a_{i j}\left(t, \alpha_{0}, \beta_{0}\right)\right]$ is an $n \times n$ matrix given by

$$
\begin{aligned}
A\left(t, \alpha_{0}, \beta_{0}\right) & \equiv f_{x}\left(t, \alpha_{0}\right)+\phi_{x}\left(t, \alpha_{0}\right)-\phi_{x}\left(t, \beta_{0}\right) \\
& =F_{x}\left(t, \alpha_{0}\right)-\phi_{x}\left(t, \beta_{0}\right),
\end{aligned}
$$

where $F_{x}=f_{x}+\phi_{x}$.

Then, there exist monotone sequences $\left\{\alpha_{n}(t)\right\},\left\{\beta_{n}(t)\right\}$ which converge uniformly to the solution of (1) and the convergence is quadratic.

Proof. $\left(\mathrm{H}_{1}\right)$ in Theorem 4 implies for any $x \geq y, x, y \in \Omega$,

$$
\begin{aligned}
f(t, x) \geq & f(t, y)+\left[f_{x}(t, y)+\phi_{x}(t, y)\right] \\
& \times(x-y)-[\phi(t, x)-\phi(t, y)] .
\end{aligned}
$$


And for any

$$
\alpha_{0}(t) \leq y \leq x \leq \beta_{0}(t)
$$

we have

$$
a_{i j}(t, y, x) \geq 0, \quad i \neq j,
$$

since $a_{i j}(t, y, x) \geq a_{i j}\left(t, \alpha_{0}, \beta_{0}\right)$ by assumption $\left(\mathrm{H}_{1}\right)$.

It is also clear that for $\alpha_{0}(t) \leq y \leq x \leq \beta_{0}(t)$,

$$
\begin{aligned}
& f_{i}\left(t, x_{1}, \ldots, x_{n}\right)-f_{i}\left(t, y_{1}, \ldots, y_{n}\right) \\
& \quad \leq L_{i} \sum_{i=1}^{n}\left(x_{i}-y_{i}\right) .
\end{aligned}
$$

Let $\alpha_{1}, \beta_{1}$ be the solutions of IVPs:

$$
\begin{aligned}
{ }^{c} D^{q} \alpha_{1}= & f\left(t, \alpha_{0}\right)+\left[A\left(t, \alpha_{0}, \beta_{0}\right)\right] \\
& \times\left(\alpha_{1}-\alpha_{0}\right), \quad \alpha_{1}(0)=x_{0}, \\
{ }^{c} D^{q} \beta_{1}= & f\left(t, \beta_{0}\right)+\left[A\left(t, \alpha_{0}, \beta_{0}\right)\right] \\
& \times\left(\beta_{1}-\beta_{0}\right), \quad \beta_{1}(0)=x_{0},
\end{aligned}
$$

where $\alpha_{0}(0) \leq x_{0} \leq \beta_{0}(0)$. We will prove that $\alpha_{0} \leq \alpha_{1}, t \in J$. To do this, let $p=\alpha_{0}-\alpha_{1}$, so that $p(0) \leq 0$. Then using (20), we obtain

$$
\begin{aligned}
{ }^{c} D^{q} p & ={ }^{c} D^{q} \alpha_{0}-{ }^{c} D^{q} \alpha_{1} \\
& \leq f\left(t, \alpha_{0}\right)-\left[f\left(t, \alpha_{0}\right)+A\left(t, \alpha_{0}, \beta_{0}\right)\left(\alpha_{1}-\alpha_{0}\right)\right] \\
& =A\left(t, \alpha_{0}, \beta_{0}\right) p .
\end{aligned}
$$

Since $A\left(t, \alpha_{0}, \beta_{0}\right)$ is quasimonotone nondecreasing by assumption $\left(\mathrm{H}_{1}\right)$ to $\left(\mathrm{H}_{2}\right)$ and it follows from Corollary 3 that $p(t) \leq 0, t \in J$, proving that $\alpha_{0} \leq \alpha_{1}, t \in J$.

Now we let $p=\alpha_{1}-\beta_{0}$ and note that $p(0) \leq 0$. Also,

$$
\begin{aligned}
{ }^{c} D^{q} p & ={ }^{c} D^{q} \alpha_{1}-{ }^{c} D^{q} \beta_{0} \\
& \leq f\left(t, \alpha_{0}\right)+A\left(t, \alpha_{0}, \beta_{0}\right)\left(\alpha_{1}-\alpha_{0}\right)-f\left(t, \beta_{0}\right) ;
\end{aligned}
$$

since $\beta_{0} \geq \alpha_{0}$, using (16), we get

$$
\begin{aligned}
f\left(t, \beta_{0}\right) \geq & f\left(t, \alpha_{0}\right)+F_{x}\left(t, \alpha_{0}\right)\left(\beta_{0}-\alpha_{0}\right) \\
& -\left[\phi\left(t, \beta_{0}\right)-\phi\left(t, \alpha_{0}\right)\right] .
\end{aligned}
$$

In view of $\left(\mathrm{H}_{1}\right)$, we have

$$
\phi\left(t, \beta_{0}\right)-\phi\left(t, \alpha_{0}\right) \leq \phi_{x}\left(t, \beta_{0}\right)\left(\beta_{0}-\alpha_{0}\right),
$$

which yields

$$
f\left(t, \beta_{0}\right) \geq f\left(t, \alpha_{0}\right)+\left[F_{x}\left(t, \alpha_{0}\right)-\phi_{x}\left(t, \beta_{0}\right)\right]\left(\beta_{0}-\alpha_{0}\right) .
$$

Hence, we obtain

$$
{ }^{c} D^{q} p \leq A\left(t, \alpha_{0}, \beta_{0}\right) p
$$

this implies that $\alpha_{1}(t) \leq \beta_{0}(t), t \in J$, using Corollary 3. As a result, we have

$$
\alpha_{0}(t) \leq \alpha_{1}(t) \leq \beta_{0}(t), \quad t \in J .
$$

In a similar way, we can prove that

$$
\alpha_{0}(t) \leq \beta_{1}(t) \leq \beta_{0}(t), \quad t \in J .
$$

To show $\alpha_{1}(t) \leq \beta_{1}(t)$, we use (16), (19), and $\left(\mathrm{H}_{1}\right)$ :

$$
\begin{aligned}
{ }^{c} D^{q} \alpha_{1}= & f\left(t, \alpha_{0}\right)+\left[F_{x}\left(t, \alpha_{0}\right)-\phi_{x}\left(t, \beta_{0}\right)\right]\left(\alpha_{1}-\alpha_{0}\right) \\
\leq & f\left(t, \alpha_{1}\right)+\phi\left(t, \alpha_{1}\right)-\phi\left(t, \alpha_{0}\right) \\
& -\phi_{x}\left(t, \beta_{0}\right)\left(\alpha_{1}-\alpha_{0}\right) \\
\leq & f\left(t, \alpha_{1}\right)+\left[\int_{0}^{1} \phi_{x}\left(t, s \alpha_{1}+(1-s) \alpha_{0}\right) d s\right] \\
& \times\left(\alpha_{1}-\alpha_{0}\right)-\phi_{x}\left(t, \beta_{0}\right)\left(\alpha_{1}-\alpha_{0}\right) \\
\leq & f\left(t, \alpha_{1}\right)+\phi_{x}\left(t, \alpha_{1}\right)\left(\alpha_{1}-\alpha_{0}\right) \\
& -\phi_{x}\left(t, \beta_{0}\right)\left(\alpha_{1}-\alpha_{0}\right) \\
\leq & f\left(t, \alpha_{1}\right) .
\end{aligned}
$$

Using a similar argument, it is easy to show that

$$
{ }^{c} D^{q} \beta_{1} \geq f\left(t, \beta_{1}\right),
$$

And, therefore, by Lemma 2 and (19), it follows that

$$
\alpha_{1}(t) \leq \beta_{1}(t), \quad t \in J
$$

by (19), we have $f$ is Lipschitzian in $x$ on $\Omega$. This proves that

$$
\alpha_{0}(t) \leq \alpha_{1}(t) \leq \beta_{1}(t) \leq \beta_{0}(t), \quad t \in J .
$$

Now assume that for some $k>1$,

$$
\alpha_{k-1}(t) \leq \alpha_{k}(t) \leq \beta_{k}(t) \leq \beta_{k-1}(t), \quad t \in J .
$$

We now aim to show that

$$
\alpha_{k}(t) \leq \alpha_{k+1}(t) \leq \beta_{k+1}(t) \leq \beta_{k}(t), \quad t \in J,
$$

where $\alpha_{k+1}(t)$ and $\beta_{k+1}(t)$ are the solutions of linear IVPs:

$$
\begin{aligned}
{ }^{c} D^{q} \alpha_{k+1}= & f\left(t, \alpha_{k}\right)+\left[F_{x}\left(t, \alpha_{k}\right)-\phi_{x}\left(t, \beta_{k}\right)\right] \\
& \times\left(\alpha_{k+1}-\alpha_{k}\right), \quad \alpha_{k+1}(0)=x_{0}, \\
{ }^{c} D^{q} \beta_{k+1}= & f\left(t, \beta_{k}\right)+\left[F_{x}\left(t, \alpha_{k}\right)-\phi_{x}\left(t, \beta_{k}\right)\right] \\
& \times\left(\beta_{k+1}-\beta_{k}\right), \quad \beta_{k+1}(0)=x_{0} .
\end{aligned}
$$

Now, set $p=\alpha_{k}-\alpha_{k+1}$ so that

$$
\begin{aligned}
{ }^{c} D^{q} p= & { }^{c} D^{q} \alpha_{k}-{ }^{c} D^{q} \alpha_{k+1} \\
\leq & f\left(t, \alpha_{k}\right)-\left[f\left(t, \alpha_{k}\right)+\left(F_{x}\left(t, \alpha_{k}\right)-\phi_{x}\left(t, \beta_{k}\right)\right)\right. \\
& \left.\times\left(\alpha_{k+1}-\alpha_{k}\right)\right] \\
= & F_{x}\left(t, \alpha_{k}\right)-\phi_{x}\left(t, \beta_{k}\right) p \\
= & A\left(t, \alpha_{k}, \beta_{k}\right) p
\end{aligned}
$$


and $p(0)=0$. It follows from Corollary 3 and using (16) that

$$
\alpha_{k}(t) \leq \alpha_{k+1}(t), \quad t \in J
$$

On the other hand, letting $p=\alpha_{k+1}-\beta_{k}$ yields

$$
\begin{aligned}
{ }^{c} D^{q} p= & { }^{c} D^{q} \alpha_{k+1}-{ }^{c} D^{q} \beta_{k} \\
\leq & f\left(t, \alpha_{k}\right)+\left[F_{x}\left(t, \alpha_{k}\right)-\phi_{x}\left(t, \beta_{k}\right)\right] \\
& \times\left(\alpha_{k+1}-\alpha_{k}\right)-f\left(t, \beta_{k}\right) .
\end{aligned}
$$

Since $\beta_{k} \geq \alpha_{k},(16)$ and $\left(\mathrm{H}_{1}\right)$ give, as before,

$$
f\left(t, \beta_{k}\right) \geq f\left(t, \alpha_{k}\right)+\left[F_{x}\left(t, \alpha_{k}\right)-\phi_{x}\left(t, \beta_{k}\right)\right]\left(\beta_{k}-\alpha_{k}\right),
$$

which shows that

$$
{ }^{c} D^{q} p \leq\left[F_{x}\left(t, \alpha_{k}\right)-\phi_{x}\left(t, \beta_{k}\right)\right] p=A\left(t, \alpha_{k}, \beta_{k}\right) p .
$$

This proves that $p(t) \leq 0$ using Corollary 3 and (16), since $p(0)=0$. Hence, we get

$$
\alpha_{k}(t) \leq \alpha_{k+1}(t) \leq \beta_{k}(t), \quad t \in J
$$

Similarly, we can prove that

$$
\alpha_{k}(t) \leq \beta_{k+1}(t) \leq \beta_{k}(t), \quad t \in J .
$$

Also, by (16), (35), and the fact that $\alpha_{k+1} \geq \alpha_{k}$, we obtain

$$
\begin{aligned}
{ }^{c} D^{q} \alpha_{k+1} \leq & f\left(t, \alpha_{k+1}\right)+\phi\left(t, \alpha_{k+1}\right)-\phi\left(t, \alpha_{k}\right) \\
& -\phi_{x}\left(t, \beta_{k}\right)\left(\alpha_{k+1}-\alpha_{k}\right) \\
\leq & f\left(t, \alpha_{k+1}\right)+\left[\int_{0}^{1} \phi_{x}\left(t, s \alpha_{k+1}+(1-s) \alpha_{k}\right) d s\right] \\
& \times\left(\alpha_{k+1}-\alpha_{k}\right)-\phi_{x}\left(t, \beta_{k}\right)\left(\alpha_{k+1}-\alpha_{k}\right) \\
\leq & f\left(t, \alpha_{k+1}\right)+\phi_{x}\left(t, \alpha_{k+1}\right)\left(\alpha_{k+1}-\alpha_{k}\right) \\
& -\phi_{x}\left(t, \beta_{k}\right)\left(\alpha_{k+1}-\alpha_{k}\right) \\
\leq & f\left(t, \alpha_{k+1}\right) .
\end{aligned}
$$

Using a similar argument, we have, as before, ${ }^{c} D^{q} \beta_{k+1} \geq$ $f\left(t, \beta_{k+1}\right)$, and hence Lemma 2 shows that

$$
\alpha_{k+1}(t) \leq \beta_{k+1}(t), \quad t \in J .
$$

By (19), we have that $f$ is Lipschitzian in $x$ on $\Omega$ and is quasimonotone nondecreasing in $x$. This proves (34). Therefore, by induction, we have for all $n$ :

$$
\begin{aligned}
\alpha_{0}(t) & \leq \alpha_{1}(t) \leq \cdots \leq \alpha_{n}(t) \leq \beta_{n}(t) \\
& \leq \cdots \beta_{1}(t) \leq \beta_{0}(t), \quad t \in J
\end{aligned}
$$

Employing the standard procedure, it is now easy to prove that the sequences $\left\{\alpha_{n}(t)\right\}$ and $\left\{\beta_{n}(t)\right\}$ converge uniformly and monotonically to the unique solution of (1) on $J$.
We will now show that the convergence of $\left\{\alpha_{n}(t)\right\}$ and $\left\{\beta_{n}(t)\right\}$ to $x(t)$ is quadratic. First set

$$
p_{n+1}=x-\alpha_{n+1}, \quad r_{n+1}=\beta_{n+1}-x, \quad t \in J,
$$

so that $p_{n+1}(0)=r_{n+1}(0)=0$. Then using integral mean value theorem and the fact that $x \geq \alpha_{n+1}$ and $\left(\mathrm{H}_{1}\right)$, we get

$$
\begin{aligned}
{ }^{c} D^{q} p_{n+1}= & { }^{c} D^{q} x-{ }^{c} D^{q} \alpha_{n+1} \\
= & f(t, x)-\left[f\left(t, \alpha_{n}\right)+\left(F_{x}\left(t, \alpha_{n}\right)-\phi_{x}\left(t, \beta_{n}\right)\right)\right. \\
& \left.\times\left(\alpha_{n+1}-\alpha_{n}\right)\right] \\
= & F(t, x)-F\left(t, \alpha_{n}\right)-\left[F_{x}\left(t, \alpha_{n}\right)-\phi_{x}\left(t, \beta_{n}\right)\right] \\
& \times\left(\alpha_{n+1}-\alpha_{n}\right)-\left[\phi(t, x)-\phi\left(t, \alpha_{n}\right)\right] \\
= & \left(\int_{0}^{1} F_{x}\left(t, s x+(1-s) \alpha_{n}\right) d s\right) p_{n} \\
& -\left[F_{x}\left(t, \alpha_{n}\right)-\phi_{x}\left(t, \beta_{n}\right)\right]\left(-p_{n+1}+p_{n}\right) \\
& -\left[\int_{0}^{1} \phi_{x}\left(t, s x+(1-s) \alpha_{n}\right) d s\right]\left(x-\alpha_{n}\right) \\
\leq & \left(F_{x}(t, x)-F_{x}\left(t, \alpha_{n}\right)\right) p_{n}+\left(\phi_{x}\left(t, \beta_{n}\right)\right. \\
& \left.-\phi_{x}\left(t, \alpha_{n}\right)\right) p_{n}+f_{x}\left(t, \alpha_{n}\right) p_{n+1} .
\end{aligned}
$$

So, we get

$$
\begin{aligned}
{ }^{c} D^{q} p_{n+1} \leq & p_{n}^{T}\left[\int_{0}^{1} F_{x x}\left(t, s x+(1-s) \alpha_{n}\right) d s\right] p_{n} \\
& +\left(r_{n}+p_{n}\right)^{T}\left[\int_{0}^{1} \phi_{x x}\left(t, s \beta_{n}+(1-s) \alpha_{n}\right) d s\right] \\
& +f_{x}\left(t, \alpha_{n}\right) p_{n+1} \\
\leq & M p_{n+1}+W\left(p_{n} \cdot p_{n}\right)+N\left(r_{n}+p_{n}\right) p_{n} \\
\leq & M p_{n+1}+\left(W+\frac{3 N}{2}\right)\left|p_{n}\right|^{2}+\frac{N}{2}\left|r_{n}\right|^{2},
\end{aligned}
$$

where $\left|p_{n}\right|^{2}=\left(\left|p_{n 1}\right|^{2},\left|p_{n 2}\right|^{2}, \ldots,\left|p_{n n}\right|^{2}\right),\left|r_{n}\right|=\left(\left|r_{n 1}\right|^{2},\left|r_{n 2}\right|^{2}\right.$, $\left.\ldots,\left|r_{n n}\right|^{2}\right), f_{x} \leq M, \sum_{i=1}^{n} f_{x x}^{i} \leq W$ and $\sum_{i=1}^{n} \phi_{x x}^{i} \leq N$ in $\Omega$, and $M, W$, and $N$ are $n \times n$ positive matrices. Using (2) to (4), we can get

$$
\begin{aligned}
p_{n+1}(t) \leq & {\left[\left(W+\frac{3 N}{2}\right)\left|p_{n}\right|^{2}+\frac{N}{2}\left|r_{n}\right|^{2}\right] } \\
& \times\left(T-t_{0}\right)^{q-1} E_{q, q}\left(M\left(T-t_{0}\right)^{q}\right)^{k} \\
\leq & V\left[\left(W+\frac{3 N}{2}\right)\left|p_{n}\right|^{2}+\frac{N}{2}\left|r_{n}\right|^{2}\right],
\end{aligned}
$$

where $V=\left(T-t_{0}\right)^{q-1} E_{q, q}\left(M\left(T-t_{0}\right)^{q}\right)^{k}$. Thus, we have

$$
\left|p_{n+1}\right| \leq V\left[\left(W+\frac{3 N}{2}\right)\left|p_{n}\right|^{2}+\frac{N}{2}\left|r_{n}\right|^{2}\right] .
$$


Similarly, we have

$$
\left|r_{n+1}\right| \leq V\left[\frac{W}{2}\left|p_{n}\right|^{2}+\left(\frac{3 W}{2}+\frac{5 N}{2}\right)\left|r_{n}\right|^{2}\right] .
$$

The proof is complete.

\section{Acknowledgments}

The authors would like to thank the reviewers for their valuable suggestions and comments. This work is supported by the National Natural Science Foundation of China (11271106) and the Natural Science Foundation of Hebei Province of China (A2013201232).

\section{References}

[1] K. S. Miller and B. Ross, An Introduction to the Fractional Calculus and Differential Equations, John Wiley \& Sons, New York, NY, USA, 1993.

[2] I. Podlubny, Fractional Differential Equations, vol. 198, Academic Press, San Diego, Calif, USA, 1999.

[3] A. A. Kilbas, H. M. Srivastava, and J. J. Trujillo, Theory and Applications of Fractional Differential Equations, vol. 204 of North-Holland Mathematics Studies, Elsevier Science B.V., Amsterdam, The Netherlands, 2006.

[4] B. J. West, M. Bologna, and P. Grigolini, Physics of Fractal Operators, Springer, New York, NY, USA, 2003.

[5] L. Debnath, "Recent applications of fractional calculus to science and engineering," International Journal of Mathematics and Mathematical Sciences, vol. 2003, no. 54, pp. 3413-3442, 2003.

[6] Y. Rossikhin and M. V. Shitikova, "Applications of fractional calculus to dynamic problems of linear and nonlinear hereditary mechanics of solids," Applied Mechanics Reviews, vol. 50, no. 1, pp. 15-67, 1997.

[7] N. M. Fonseca Ferreira, F. B. Duarte, M. F. M. Lima, M. G. Marcos, and J. A. Tenreiro Machado, "Application of fractional calculus in the dynamical analysis and control of mechanical manipulators," Fractional Calculus \& Applied Analysis, vol. 11, no. 1, pp. 91-113, 2008.

[8] V. Lakshmikantham and A. S. Vatsala, "Basic theory of fractional differential equations," Nonlinear Analysis, vol. 69, no. 8, pp. 2677-2682, 2008.

[9] Z. Denton and A. S. Vatsala, "Fractional integral inequalities and applications," Computers \& Mathematics with Applications, vol. 59, no. 3, pp. 1087-1094, 2010.

[10] C. B. Zhai, W. P. Yan, and C. Yang, "A sum operator method for the existence and uniqueness of positive solutions to RiemannLiouville fractional differential equation boundary value problems," Communications in Nonlinear Science and Numerical Simulation, vol. 18, no. 4, pp. 858-866, 2013.

[11] V. Lakshmikantham, "Theory of fractional functional differential equations," Nonlinear Analysis, vol. 69, no. 10, pp. 3337-3343, 2008.

[12] T. Jankowski, "Fractional differential equations with deviating arguments," Dynamic Systems and Applications, vol. 17, no. 3-4, pp. 677-684, 2008.

[13] M. Benchohra, J. Henderson, S. K. Ntouyas, and A. Ouahab, "Existence results for fractional order functional differential equations with infinite delay," Journal of Mathematical Analysis and Applications, vol. 338, no. 2, pp. 1340-1350, 2008.
[14] B. Ahmad and S. Sivasundaram, "Existence of solutions for impulsive integral boundary value problems of fractional order," Nonlinear Analysis, vol. 4, no. 1, pp. 134-141, 2010.

[15] W. Deng, "Numerical algorithm for the time fractional FokkerPlanck equation," Journal of Computational Physics, vol. 227, no. 2, pp. 1510-1522, 2007.

[16] T. Jankowski, "Fractional equations of Volterra type involving a Riemann-Liouville derivative," Applied Mathematics Letters, vol. 26, no. 3, pp. 344-350, 2013.

[17] M. M. El-Borai, K. E.-S. El-Nadi, and H. A. Fouad, "On some fractional stochastic delay differential equations," Computers \& Mathematics with Applications, vol. 59, no. 3, pp. 1165-1170, 2010.

[18] J. Henderson and A. Ouahab, "Impulsive differential inclusions with fractional order," Computers \& Mathematics with Applications, vol. 59, no. 3, pp. 1191-1226, 2010.

[19] V. Lakshmikantham and A. S. Vatsala, "General uniqueness and monotone iterative technique for fractional differential equations," Applied Mathematics Letters, vol. 21, no. 8, pp. 828$834,2008$.

[20] F. A. McRae, "Monotone iterative technique and existence results for fractional differential equations," Nonlinear Analysis, vol. 71, no. 12, pp. 6093-6096, 2009.

[21] M. Benchohra and S. Hamani, "The method of upper and lower solutions and impulsive fractional differential inclusions," Nonlinear Analysis, vol. 3, no. 4, pp. 433-440, 2009.

[22] V. Lakshmikantham and A. S. Vatsala, Generalized Quasilinearization for Nonlinear Problems, Kluwer Academic Publishers, Dordrecht, The Netherlands, 1998.

[23] J. Vasundhara Devi and Ch. Suseela, "Quasilinearization for fractional differential equations," Communications in Applied Analysis, vol. 12, no. 4, pp. 407-418, 2008.

[24] J. Vasundhara Devi, F. A. McRae, and Z. Drici, "Generalized quasilinearization for fractional differential equations," Computers \& Mathematics with Applications, vol. 59, no. 3, pp. 10571062, 2010. 


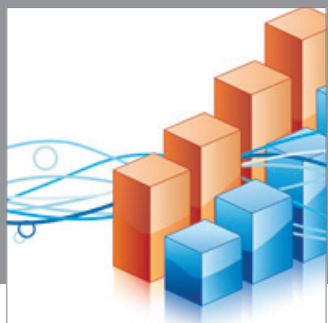

Advances in

Operations Research

mansans

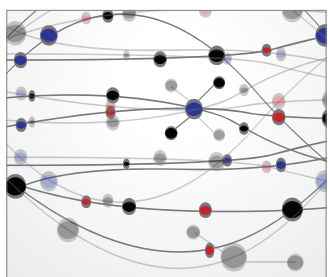

The Scientific World Journal
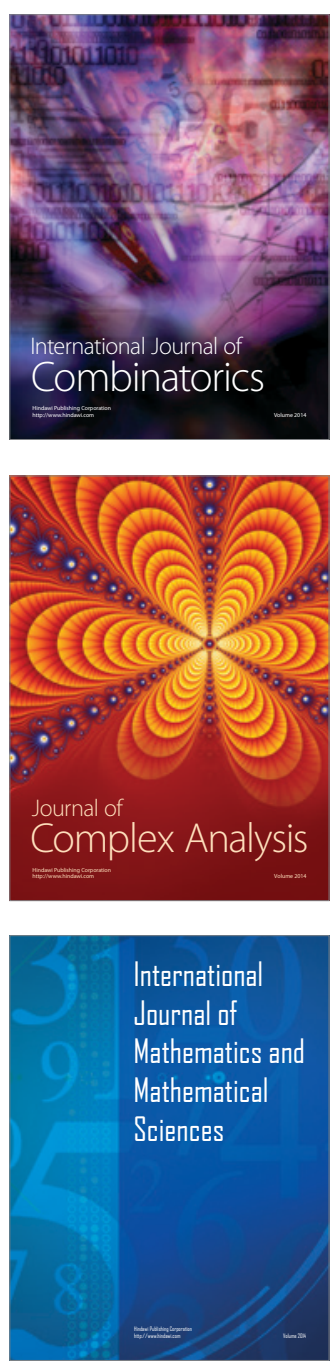
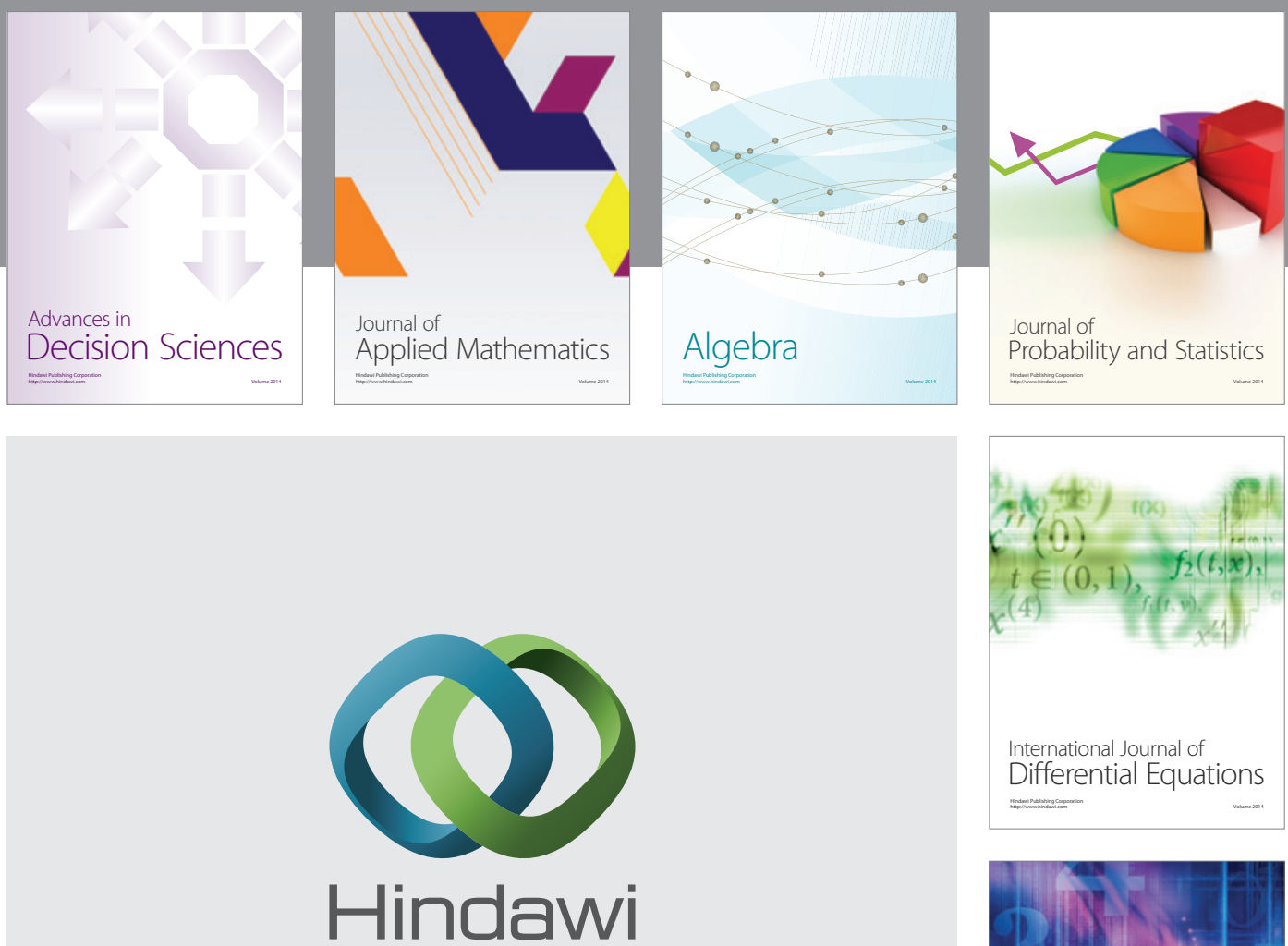

Submit your manuscripts at http://www.hindawi.com
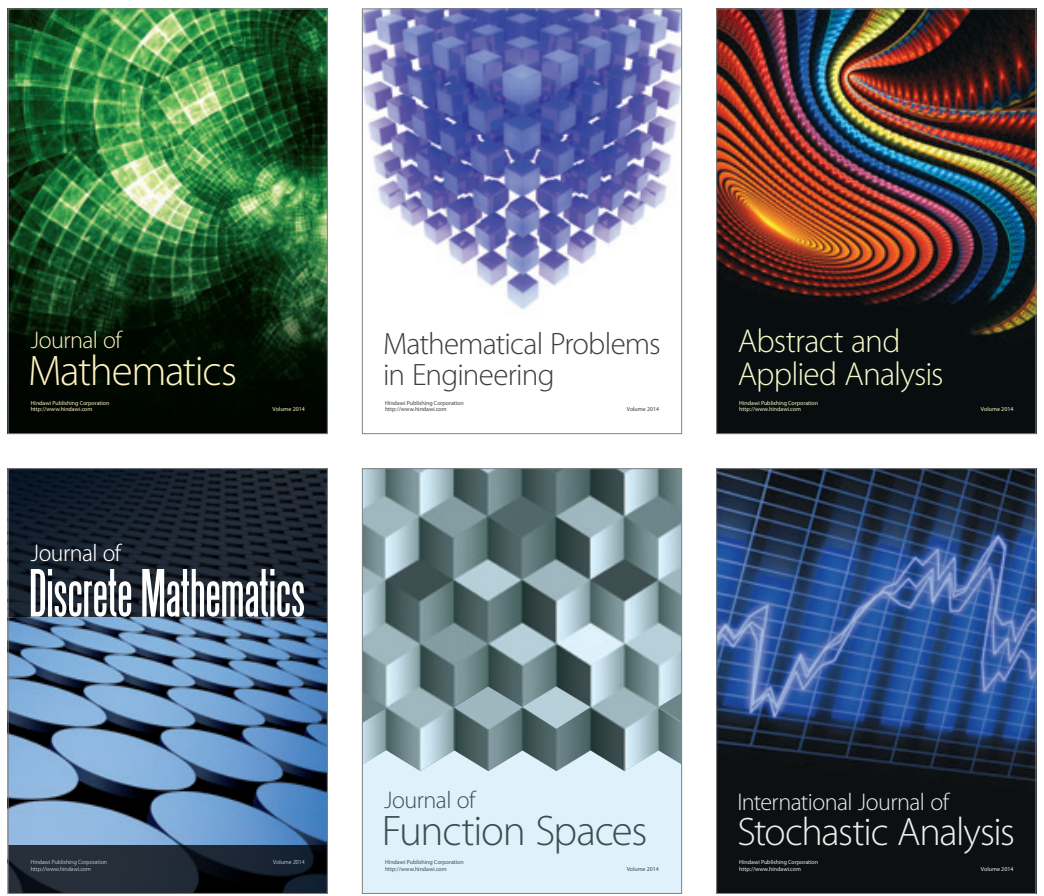

Journal of

Function Spaces

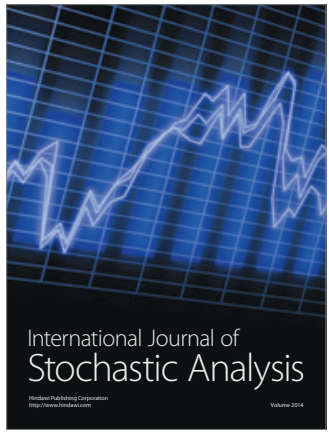

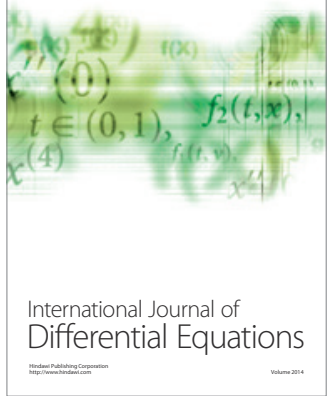
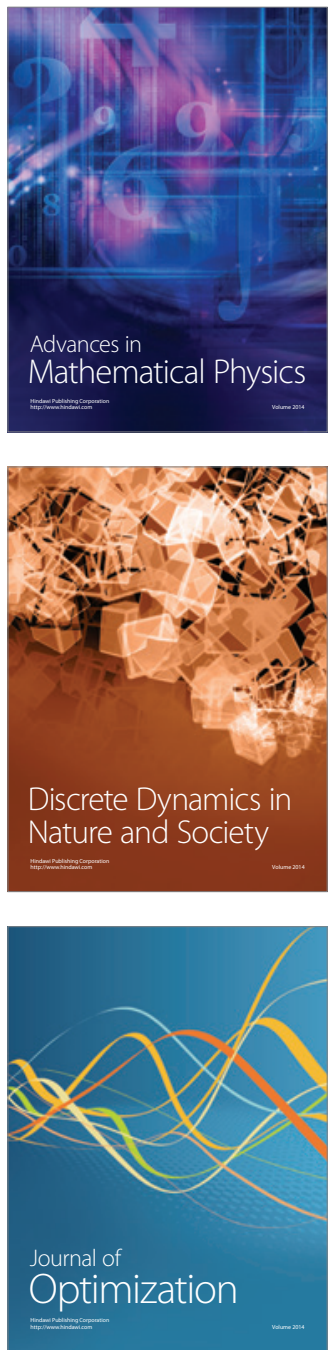